\title{
Clostridium diffcile infection in patients with end stage renal disease. Is it preventable?
}

\author{
Łukasz Lis, Andrzej Konieczny, Kinga Żłobicka, Wojciech Witkiewicz and Zbigniew Hruby* \\ Research and Development Center, Provincial Specialist Hospital in Wrocław, Poland
}

\begin{abstract}
Clostridium difficile infection (CDI) is a leading cause of a healthcare-associated diarrhea worldwide. Recently, an increased number of new cases and growing mortality due to CDI have been observed. Patients suffering from end-stage renal disease (ESRD) are highly exposed to CDI. It has been proven that CDI in patients receiving renal replacement therapy (RRT) significantly increases mortality, prolongs hospitalization and increases the cost of treatment. Important risk factors of CDI in ERSD patients include hospitalization or stay in an intensive care unit in the last 90 days, HIV infection, bacteraemia, prolonged antibiotic therapy and hypoalbuminemia. Cirrhosis, age over 65 years, hypoalbuminaemia, longer hospitalization time and use of antibiotics are significant risk factors of death in these patients. Effective methods of preventing CDI include hand hygiene, isolation of infected patients, the use of masks, gloves, disinfection of the environment and systematic education and control of medical personnel, as well as rational antibiotic policy. In addition, it is important to avoid antibiotics with a proven risk of CDI, cautious use of proton pump inhibitors (PPI) and $\mathrm{H} 2$ receptor antagonists. It is also important in the prevention of CDI, in people with ERSD, to apply fast diagnostics right from the onset of the first symptoms. Use of probiotics and bile acids in the primary prevention of CDI requires further research. It seems that knowledge of these factors and methods of prevention will significantly reduce morbidity and mortality caused by the CDI.
\end{abstract}

\section{Introduction}

Pseudomembranous colitis caused by Clostridium difficile is one of the most leading causes of diarrhea among hospitalized patients [1]. However, more recently there has also been a significant increase in environmental (non-hospital) C. difficile infections (CDI) [2]. Their epidemiology and risk factors are not yet fully understood, however, it is estimated that the prevalence could be as high as $41 \%$ among all CDIs [3]. Among the most vulnerable patients, both for hospital and community-acquired infections are those suffering from endstage renal disease (ESRD) [4]. The explanation for this fact is, among the others, the frequent use of antibiotics, the need for permanent outpatient dialysis, and a more frequent need for hospital admission, both urgent and planned. It has been proven that CDI in patients treated with renal replacement therapy (RRT), by hemodialysis, results in prolonged hospitalization, is usually more severe, increases mortality and significantly multiplies costs. It may cause a serious problem and at the same time is calling for strategies to counteract its prevalence [4].

CDI is caused by a Gram-positive, obligatory anaerobic, sporeforming bacillus, resistant to high temperature, as well as to hydrochloric acid and antibiotics. CDI is transferred by the fecal-oral route. The spores are transformed in the small intestine into vegetative forms, capable of producing toxin A and/or toxin B and binary toxin, which are the main causes of virulence of this bacterium. They cause damage to the intestinal mucosa, which in turn leads to the development of colitis, the formation of purulent membranes and diarrhea [5-7]. This disease, in most cases, proceeds mildly, in some patients is asymptomatic, but can also lead to severe dehydration, hypo-albuminemia, septic shock, and even death, in extremely severe cases [8]. In 2005, the first strain of $C$. difficile, named North American PFGE type 1 NAP1/BI/027 was described, with significantly greater virulence producing 16 times more toxin A and 23 times more toxin B, compared to previous strains. This strain is responsible for the recent CDI outbreaks, causing more severe disease and it is responsible for higher mortality [9].
Recognized risk factors of CDI are the following: antibiotic therapy, use of proton pump inhibitors (PPIs), antidepressants, nonsteroidal anti-inflammatory drugs (NSAIDs), advanced age, vitamin-D deficiency, prolonged hospitalization, chronic diseases, chemotherapy, immunosuppression, gastric tube feeding and post-operative milieu in the abdominal cavity [10-12]. Many studies published in recent years indicate a greater incidence rate and mortality due to CDI in patients with chronic kidney disease (CKD), especially those in the ESRD phase, in comparison to the general population $[13,14]$.

The aim of this study is to outline the risk factors of a CDI outbreak in ESRD patients and to assess possible methods of prevention of its perpetuation and propagation.

For this review, original articles, meta-analyses, and reviews have been considered. We searched the PubMed database for English language references published from 1990 to 2019, crossing the terms: "Clostridium difficile" or "Pseudomembranous colitis", "End-stage renal disease" and "Chronic renal failure"

\section{Clostridium difficile infection in ESRD patients}

The population of ESRD patients is constantly growing. According to the latest data from The United States Renal Data System (USRDS), in 2016 there was a total of 724075 people suffering from ESRD,

${ }^{*}$ Correspondence to: Zbigniew Hruby, MD, PhD’ Department of Nephrology, Diabetology and Transplantology Voividship Speciality Hospital 73a, Kamienskiego Street 51 - 124 Wroclaw, Poland, Tel: +048 603805 207; E-mail: Hruby@wssk.wroc.pl

Key words: end-stage renal disease, pseudomembranous enterocolitis, clostridium difficile

Received: May 17, 2019; Accepted: June 14, 2019; Published: June 17, 2019 
of which 457957 required RRT by hemodialysis, 51057 were on peritoneal dialysis (PD) and over 215000 underwent successful kidney transplantation (KTx) [15]. Patients on maintenance dialysis are a specific group, strongly exposed not only to hospital infection with $C$. difficile etiology but also to environmental hazards. In this group, the incidence of infection is estimated at about $4.25 \%$ and is even $2-3$ times higher than in the general population $[4,16]$. This is most likely due to the fact, that patients with ESRD are more often hospitalized, require frequent use of antibiotics or intervention in the emergency department, which, as a recent report has documented, may be one of the main reservoirs of $C$. difficile environmental infection [17]. In addition, these patients are chronically subjected to repeated hemodialysis sessions at least three times a week, at the outpatient dialysis center, which also has been recognized as an environmental risk of CDI [18]. According to the data included in the USRDS, in 2016 a patient with ESRD was admitted to the hospital on average 1.7 times. For comparison, in the general population, this rate was 0.1 times [19].

It was also demonstrated that patients with CKD have a reduced gastric acid secretion and bacterial outgrowth, caused by abnormalities of peristalsis, which in turn facilitates bacterial colonization and subsequent occurrence of infection [20]. Those factors are associated with increased susceptibility to infection of various etiologies, in course of uremia [21].

The vast majority of recent publications confirmed that CDI in patients receiving renal replacement therapy with dialysis significantly increases mortality, prolongs hospitalization and significantly raises the cost of care $[4,16]$. Pant, et al. showed that among patients with ESRD, who suffered from CDI, compared to those without CDI, the duration of hospitalization is on average longer by 9 days, hospitalization costs by on an average of 68 thousand dollars, and mortality even twice as high [16]. In a similar publication, comparing patients with and without ESRD, infected by C. difficile, higher mortality, longer mean hospital stay time (9 vs. 7 days) and higher costs of hospitalization ( $\$ 35588$ vs. $\$ 23505$ respectively) were found [22].

In a study in ESRD patients in Mexico, it was found that the most common symptoms of CDI, except diarrhea, were abdominal pain and bloating. Fever occurred less frequently, while in additional studies, the presence of leukocytes in the stool was characteristic [23]. In one of the last papers dealing with CDI in patients with ERSD, risk factors of infection, death, and recurrence of infection were examined at the onset of observation. It has been shown that important risk factors include: hospitalization in general wards or stay in an intensive care unit, in the preceding 90 days, age over 65 years, human immunodeficiency virus (HIV) infection and bacteremia. HIV infection increased the risk 2.6 times compared to sero-negative patients [4]. Additional risk factors were pneumonia, rheumatoid arthritis (RA), hepatitis C virus (HCV), urosepsis, gastrointestinal tract bleeding and diabetes. Among people of Latino American origin and in African Americans, there was a lower incidence of CDI, in contrast to Caucasians, which accounted for $72.5 \%$ of all patients [4].

In addition, this study demonstrated liver cirrhosis and age over 65 years to be significant risk factors for death in patients with ESRD, infected by $C$. difficile. The risk of death was also increased, although to a lesser extent, by a peptic ulcer, leucopenia, HCV and HIV infection, hospitalization in the intensive care unit, laparotomy and gastrointestinal bleeding. Kidney transplant recipients, patients treated by peritoneal dialysis and patients of Latino American origin were less likely to have a lower risk of death in the examined population [4].
Other significant risk factors for CDI in ESRD patients might include hypoalbuminemia and prolonged hospitalization. On the other hand hypoalbuminemia, prolonged hospitalization and frequent use of antibiotics were regarded as risk factors of death, as demonstrated in our previous study [13]. Although it concerned patients with CKD at various stages, it should be emphasized that $67 \%$ of patients, positive for the presence of $C$. difficile, had advanced chronic kidney insufficiency.

The incidence of CDI recurrence in patients with ESRD is estimated at approximately $23.6 \%$, and the risk factors include age and Caucasian origin [4]. Unlike the general population, in a study, published by Tirath, et al. the relapse rate was neither affected by hospitalization nor its duration [4].

At present, there are no specific recommendations regarding treatment of CDI in subjects with ESRD. First and foremost, antibiotic therapy should be discontinued as fast as possible. In the initial treatment of mild CDI either vancomycin or fidaxomicin, rather than metronidazole, is recommended. For fulminant CDI, vancomycin administered orally is the medication of choice [24]. There was no advantage of vancomycin over fidaxomicin. Further-more in case of fidaxomicin, a reduced number of CDI recurrences and greater efficacy were found $[25,26]$. However, the high cost of fidaxomicin treatment, remains a major problem. Bezlotoxumab, a human monoclonal antibody, against Clostridium difficile toxin B, was recently approved by FDA, to reduce CDI's recurrence in high-risk adults, receiving antibiotic therapy for CDI. Given its high cost, it should be reserved for patients at high risk for recurrence, in order to make it cost-effective [27,28]. Fecal transplantation is a method of choice in dialysis patients with recurrent CDI, however, data on its efficacy and safety are still inadequate [29].

\section{Methods of preventing CDI in patients with ESRD and in the general population}

Over the past 15 years, there has been a significant increase in the incidence of CDI and a much more severe course has been observed [30]. This applies to both patients treated by hemodialysis and to the general population. It is estimated that in the United States, CDI now accounts for as many as $15-25 \%$ of all antibiotic-related diarrhea cases, with mortality oscillating around $3-15 \%$, with $20 \%$ relapse rate and total annual treatment cost of 4 billion dollars [31,32]. There is an increasing number of deaths caused by $\mathrm{CDI}$, including patients with ESRD. The latter association linked with the occurrence of an epidemic, hyper-virulent strain BI/NAP1/027 and the fact of starting RRT by increasingly elderly patients, with several concomitant diseases [4].

The CDI prevention strategies mainly involve methods of reducing patients' exposure to the pathogen and minimize risk factors. In addition to basic practices such as hand hygiene, isolation of infected patients, the use of masks, gloves, disinfection of both the environment, medical equipment. Systematic education and control of medical personnel are always worthwhile. Nonetheless, the most important factor, impacting on a significant reduction in CDI frequency, appears to be a rational antibiotics policy [33]. The problem is very important, as it is estimated that approximately $50 \%$ of outpatient antibiotics, employed in case of respiratory tract infections, and even as much as $50 \%$ of antibiotics used in hospitals, has been prescribed without justification $[34,35]$. In studies analyzing the use of antibiotics in dental prophylaxis, it was demonstrated that in about $59 \%$ of cases the use of antibiotics was not compliant with the current guidelines [17]. These findings indicate the importance of comprehensive programs, aimed at reducing the use of unwarranted antibiotics (antibiotic stewardship programs). For this 
purpose, special infection teams have been established in hospitals, with the purpose of education, to ensure compliance with current guidelines, in order to reduce the problem of antibiotics' abuse. It is estimated that the implementation of these strategies would result in a reduction of infections caused by $C$. difficile, even by $52 \%$. These activities would apply not only to nosocomial infections but also to the increasing incidence of environmental infections [33]. It is worth mentioning that these measures would also limit the incidence of other infections, such as those caused by methicillin-resistant Staphylococcus aureus (MRSA) or Pseudomonas aeruginosa resistant to fluoroquinolones.

Another important guideline is to avoid the use of antibiotics with the proven risk of CDI, such as clindamycin, fluoroquinolones or third generation cephalosporins, as well as unnecessarily prolonging duration of therapy with these drugs. Particularly this applies to patients on maintenance dialysis who are more frequently diagnosed with pneumonia, sepsis, urinary tract infections and other conditions associated both with peritoneal dialysis and hemodialysis [36]. Recent studies have shown differences in the effects of various antibiotics on the incidence of CDI, depending on whether they were used in hospital or outpatient clinic. It has been documented that in the case of hospitalization, the use of clindamycin, cephalosporin, fluoroquinolones or carbapenems increases the risk of CDI twice, whereas in the case of ambulatory treatment, the risk increases about 8-20 times for clindamycin and 3-5 times for cephalosporin and fluoroquinolones. Another study demonstrated that macrolides increase the risk of CDI twice in outpatient settings, but do not affect the frequency of infection in a hospital setting. On the other hand, there was no increased risk of infection when using tetracycline and aminoglycosides, both in the hospital and ambulatory settings [37-40]. This work shows that sensible selection of antibiotics may reduce the risk of CDI, in patients at high risk such as dialyzed subjects.

It is also important to notice, that most studies have confirmed the effect of PPIs and $\mathrm{H} 2$ receptor antagonists, on the increased risk of CDI in the general population [41-44]. These drugs are estimated to increase the risk of infection about $1.73-2.30$ times [45]. However, there are also reports that did not confirm this relationship [46]. Given the widespread abuse of the above-mentioned drugs and at the same time reduced gastric acid secretion in dialysis patients, caution in their use is recommended, limiting their prescriptions to situations where they are necessary. This could significantly contribute to the reduction of CDI in both dialysis patients and in the general population.

Another important issue in preventing the spread of CDI is the necessity to obtain the material for laboratory testing as soon as possible. Slowing down this process delays diagnosis and subsequent isolation increasing the risk of disease transmission. Therefore, it is necessary to establish an appropriate procedure preventing delays both in the diagnosis of CDI and implementation of appropriate preventive and therapeutic measures.

Use of probiotics and bile acids' compounds is traditionally regarded important in preventing CDI, although justification by clinical trials is rather ambiguous. In the case of probiotics, there are currently no recommendations for their routine use. However, there is a moderately documented evidence on their effectiveness in the prevention of primary infection [30,47-49]. There is also insufficient evidence for their effectiveness in secondary prevention. In the recent paper, concerning the role of probiotics in CDI prevention, in the nephrology and transplantation ward, a significant reduction of the CDI incidence after administration of LP299v was observed, with
Table 1. The main methods of CDI prevention

\begin{tabular}{|c|c|}
\hline \multicolumn{2}{|c|}{ The main methods of CDI prevention } \\
\hline 1 & $\begin{array}{l}\text { Hand hygiene before and after contact of a patient with CDI and after removing } \\
\text { gloves, with either soap and water or an alcohol-based hand hygiene product. }\end{array}$ \\
\hline 2 & $\begin{array}{l}\text { Accommodate patients with CDI in a private room with a dedicated toilet, to } \\
\text { decrease transmission to other patients. }\end{array}$ \\
\hline 3 & $\begin{array}{l}\text { Use gloves and gowns on entry to a room of a patient with CDI and while caring } \\
\text { for patients with CDI. }\end{array}$ \\
\hline 4 & $\begin{array}{l}\text { Use disposable patient equipment when possible and ensure that reusable } \\
\text { equipment is thoroughly cleaned and disinfected. }\end{array}$ \\
\hline 5 & Obtain the material for CDI examination as soon as possible. \\
\hline 6 & Systematic education and control of medical personnel. \\
\hline 7 & $\begin{array}{l}\text { Use antibiotics rationally. Avoid those with proven risk of CDI } \\
\text { (fluoroquinolones, clindamycin and cephalosporins), if it's possible. Implement } \\
\text { an antibiotic stewardship program. }\end{array}$ \\
\hline 8 & $\begin{array}{l}\text { Cautious use PPIs and } \mathrm{H} 2 \text { receptor antagonists, limiting to situations where they } \\
\text { are absolutely necessary. }\end{array}$ \\
\hline
\end{tabular}

subsequent significant increase after cessation of this prophylaxis [50]. Bile acid compounds, by shaping up gut physiological flora, could be crucial in both primary and secondary prevention of infection, but further research is necessary to confirm this notion [47].

The presence of a tunneled catheter or synthetic fistula, significantly increased the risk of CDI, compared to arteriovenous access made of the patient's own vessels [18]. However, this may be due to the artificial vascular accesses described above, are used in patients with high morbidity and therefore require more frequent hospitalizations, than those in whom native vessels' fistula has been made. A substantial fraction of recent research on CDI focuses on new antibacterial agents, such as cadazolid, surotomycin, ridinilazole, LFF571 and other, as well as new methods for treatment of recurrent CDI, such as non-toxigenic C. difficile strains, monoclonal antibodies against toxins $\mathrm{A}$ and $\mathrm{B}$ (actoxumab and bezlotoxumab) and vaccines are also in sight.

Nonetheless, it should be born in mind that primary prevention (Table 1) should be given priority in arresting the escalation of CDI.

\section{Summary}

CDI is a serious problem both for patients with ESRD and in general population and as such, it associates with high costs of treatment. Patients on maintenance dialysis are a special group of individuals, in whom the disease is associated with a more severe course, greater mortality and the number of complications. Knowledge of risk factors and methods of prevention are the basic tools to combat the epidemic of nosocomial and non-hospital infections with $C$. difficile etiology. Rational antibiotic therapy, aseptic behavior, a rapid diagnosis from the onset of first symptoms and systematic education of patients and medical personnel, could significantly reduce morbidity and mortality caused by CDI, and notably, reduce costs associated with hospitalization.

\section{Conflicts of interest}

The authors declare that they have no conflicts of interest related to the contents of this article.

\section{Funding}

This research did not receive any specific grant from funding agencies in the public, commercial, or not-for-profit sectors.

\section{References}

1. Polage CR, Solnick JV, Cohen SH (2012) Nosocomial diarrhea: evaluation and treatment of causes other than Clostridium difficile. Clin Infect Dis 55: 982-989. [Crossref] 
2. Lessa FC, Mu Y, Bamberg WM, Beldavs ZG, Dumyati GK, et al. (2015) Burden of Clostridium difficile infection in the United States. $N$ Engl J Med 372: 825-834. [Crossref]

3. Dubberke ER, Nyazee HA, Yokoe DS, Mayer J, Stevenson KB, et al. (2012) Implementing automated surveillance for tracking Clostridium difficile infection at multiple healthcare facilities. Infect Control Hosp Epidemiol 33: 305-308. [Crossref]

4. Tirath A, Tadros S, Coffin SL, Kintziger KW, Waller JL, et al. (2017) Clostridium difficile infection in dialysis patients. J Investig Med 65: 353-357. [Crossref]

5. Leffler DA, Lamont JT (2015) Clostridium difficile Infection. N Engl J Med 373: $287-$ 288. [Crossref]

6. Cohen SH, Gerding DN, Johnson S, Kelly CP, Loo VG, et al. (2010) Clinical practice guidelines for Clostridium difficile infection in adults: 2010 update by the society for healthcare epidemiology of America (SHEA) and the infectious diseases society of America (IDSA). Infect Control Hosp Epidemiol 31: 431-455. [Crossref]

7. Surawicz CM, Brandt LJ, Binion DG, Ananthakrishnan AN, Curry SR, et al. (2013) Guidelines for diagnosis, treatment, and prevention of Clostridium difficile infections. Am J Gastroenterol 108: 478-498. [Crossref]

8. Lo Vecchio A, Zacur GM (2012) Clostridium difficile infection: an update on epidemiology, risk factors, and therapeutic options. Curr Opin Gastroenterol 28:1-9. [Crossref]

9. Petrella LA, Sambol SP, Cheknis A, Nagaro K, Kean Y, et al. (2012) Decreased cure and increased recurrence rates for Clostridium difficile infection caused by the epidemic C. difficile BI strain. Clin Infect Dis 55:351-357. [Crossref]

10. Daniel A, Rapose A (2015) The evaluation of Clostridium difficile infection (CDI) in a community hospital. J Infect Public Health 8:155-160. [Crossref]

11. Howell MD, Novack V, Grgurich P, Soulliard D, Novack L, et al. (2010) Iatrogenic gastric acid suppression and the risk of nosocomial Clostridium difficile infection. Arch Intern Med 170: 784-790. [Crossref]

12. Dalton BR, Lye-Maccannell T, Henderson EA, Maccannell DR, Louie TJ (2009) Proton pump inhibitors increase significantly the risk of Clostridium difficile infection in a low-endemicity, non-outbreak hospital setting. Aliment Pharmacol Ther. 29: 626634. [Crossref]

13. Lis L, Jerzak P, Konieczny A, Sroka M, Noceń-Rychlewska B, et al. (2018) Risk factors of the Clostridium difficile infection in patients with chronic kidney disease. Adv Clin Exp Med 27: 1081-1084. [Crossref]

14. Eui Oh S, Lee SM, Lee YK, Choi SR, Choi MJ, et al. (2013) Clostridium difficileassociated diarrhea in dialysis patients. Kidney Res Clin Pract 32: 27-31. [Crossref]

15. System USRD (2018) USRDS 2018 Annual Data Report: Atlas of Chronic Kidney Disease and End-Stage Renal Disease in the United States.

16. Pant C, Deshpande A, Anderson MP, Sferra TJ (2012) Clostridium difficile infection is associated with poor outcomes in end-stage renal disease. J Investig Med 60: 529-532. [Crossref]

17. Guh AY, Adkins SH, Li Q, Bulens SN, Farley MM, et al. (2017) Risk Factors for Community-Associated Clostridium difficile Infection in Adults: A Case-Control Study. Open Forum Infect Dis 4: 171. [Crossref]

18. See I, Bagchi S, Booth S, Scholz D, Geller AI, et al. (2015) Outbreak of Clostridium difficile Infections at an Outpatient Hemodialysis Facility-Michigan, 2012-2013. Infect Control Hosp Epidemiol 36: 972-974. [Crossref]

19. Wang D, Hatahet M, Wang Y (2019) Multivariate analysis of hypertension in general US adults based on the 2017 ACC/AHA guideline: data from the national health and nutrition examination survey 1999 to 2016. Blood Press 28: 191-198. [Crossref]

20. Kim SC, Seo MY, Lee JY, Kim KT, Cho E, et al. (2016) Advanced chronic kidney disease: a strong risk factor for Clostridium difficile infection. Korean J Intern Med 31:125-133. [Crossref]

21. Betjes MG (2013) Immune cell dysfunction and inflammation in end-stage renal disease. Nat Rev Nephrol 9: 255-265. [Crossref]

22. Goyal A, Chatterjee K, Yadlapati S, Rangaswami J (2017) Impact of end stage kidney disease on costs and outcomes of Clostridium difficile infection. Int J Infect Dis $62: 8$-9.

23. Morfin-Otero R, Garza-Gonzalez E, Garcia Garcia G, Perez-Gomez HR, Aguirre-Diaz SA, et al. (2018) Clostridium difficile infection in patients with chronic kidney disease in Mexico. Clin Nephrol 90: 350-356. [Crossref]

24. McDonald LC, Gerding DN, Johnson S (2018) Clinical Practice Guidelines for Clostridium difficile Infection in Adults and Children: 2017 Update by the Infectious Diseases Society of America (IDSA) and Society for Healthcare Epidemiology of America (SHEA). Clin Infect Dis 66: 987-994.
25. Mullane KM, Cornely OA, Crook DW, Golan Y, Louie TJ, et al. (2013) Renal impairment and clinical outcomes of Clostridium difficile infection in two randomized trials. Am J Nephrol 38: 1-11. [Crossref]

26. Rubio-Terres C, Cobo Reinoso J, Grau Cerrato S, Mensa Pueyo J, Salavert Lletí M, et al. (2015) Economic assessment of fidaxomicin for the treatment of Clostridium difficile infection (CDI) in special populations (patients with cancer, concomitant antibiotic treatment or renal impairment) in Spain. Eur J Clin Microbiol Infect Dis 34: 2213-2223. [Crossref]

27. Alonso CD, Mahoney MV (2018) Bezlotoxumab for the prevention of Clostridium difficile infection: a review of current evidence and safety profile. Infect Drug Resist 12: 1-9. [Crossref]

28. Chahine EB, Cho JC, Worley MV (2018) Bezlotoxumab for the Prevention of Clostridium difficile Recurrence. Consult Pharm 33: 89-97. [Crossref]

29. Lahtinen P, Mattila E, Anttila VJ, Tillonen J, Teittinen M, et al. (2017) Faecal microbiota transplantation in patients with Clostridium difficile and significant comorbidities as well as in patients with new indications: A case series.World J Gastroenterol 23: 71747184. [Crossref]

30. Cooper CC1, Jump RL2, Chopra T3 (2016) Prevention of Infection Due to Clostridium difficile. Infect Dis Clin North Am 30: 999-1012. [Crossref]

31. Evans CT, Safdar N (2015) Current Trends in the Epidemiology and Outcomes of Clostridium difficile Infection. Clin Infect Dis 60 Suppl 2: S66-71. [Crossref]

32. Davies KA, Ashwin H, Longshaw CM, Burns DA, Davis GL, et al. (2016) Diversity of Clostridium difficile PCR ribotypes in Europe: results from the European, multicentre, prospective, biannual, point-prevalence study of Clostridium difficile infection in hospitalised patients with diarrhoea (EUCLID), 2012 and 2013. Euro Surveill pp: 21. [Crossref]

33. Feazel LM, Malhotra A, Perencevich EN, Kaboli P, Diekema DJ, et al. (2014) Effect of antibiotic stewardship programmes on Clostridium difficile incidence: a systematic review and meta-analysis. J Antimicrob Chemother 69: 1748-1754. [Crossref]

34. Fleming-Dutra KE, Hersh AL, Shapiro DJ, Bartoces M, Enns EA, et al. (2016) Prevalence of Inappropriate Antibiotic Prescriptions Among US Ambulatory Care Visits, 2010-2011. JAMA 315: 1864-1873. [Crossref]

35. Willemsen I, Groenhuijzen A, Bogaers D, Stuurman A, van Keulen P, et al. (2007) Appropriateness of antimicrobial therapy measured by repeated prevalence surveys. Antimicrob Agents Chemother 51: 864-867. [Crossref]

36. Eleftheriadis T, Liakopoulos V, Leivaditis K, Antoniadi G, Stefanidis I (2011) Infections in hemodialysis: a concise review - Part 1: bacteremia and respiratory infections. Hippokratia 15: 12-17. [Crossref]

37. Furuya-Kanamori L, Stone JC, Clark J, McKenzie SJ, Yakob L, et al. (2015) Comorbidities, Exposure to Medications, and the Risk of Community-Acquired Clostridium difficile Infection: a systematic review and meta-analysis. Infect Control Hosp Epidemiol 36: 132-141. [Crossref]

38. Brown KA, Khanafer N, Daneman N, Fisman DN (2013) Meta-analysis of antibiotics and the risk of community-associated Clostridium difficile infection. Antimicrob Agents Chemother 57: 2326-2332. [Crossref]

39. Deshpande A, Pasupuleti V, Thota P, Pant C, Rolston DD, et al. (2013) Communityassociated Clostridium difficile infection and antibiotics: a meta-analysis. J Antimicrob Chemother 68: 1951-1961. [Crossref]

40. Slimings C, Riley TV (2014) Antibiotics and hospital-acquired Clostridium difficile infection: update of systematic review and meta-analysis. J Antimicrob Chemother 69: 881-891. [Crossref]

41. Gordon D, Young LR, Reddy S, Bergman C, Young JD (2016) Incidence of Clostridium difficile infection in patients receiving high-risk antibiotics with or without a proton pump inhibitor. $J$ Hosp Infect 92: 173-177. [Crossref]

42. Kwok CS, Arthur AK, Anibueze CI, Singh S, Cavallazzi R, et al (2012) Risk of Clostridium difficile infection with acid suppressing drugs and antibiotics: metaanalysis. Am J Gastroenterol 107: 1011-1019. [Crossref]

43. McDonald EG, Milligan J, Frenette C, Lee TC (2015) Continuous Proton Pump Inhibitor Therapy and the Associated Risk of Recurrent Clostridium difficile Infection. JAMA Intern Med 175: 784-791. [Crossref]

44. Tleyjeh IM, Abdulhak AB, Riaz M, Garbati MA, Al-Tannir M, et al. (2013) The association between histamine 2 receptor antagonist use and Clostridium difficile infection: a systematic review and meta-analysis. PLoS One 8: e56498. [Crossref]

45. Trifan A, Stanciu C, Girleanu I, Stoica OC1, Singeap AM, et al. (2017) Proton pump inhibitors therapy and risk of Clostridium difficile infection: Systematic review and meta-analysis. World J Gastroenterol 23: 6500-6515. [Crossref] 
46. Novack L, Kogan S, Gimpelevich L, Soulliard D, Novack L, et al. (2014) Acid suppression therapy does not predispose to Clostridium difficile infection: the case of the potential bias. PLoS One 9: e110790. [Crossref]

47. Cataldo MA, Granata G, Petrosillo N (2017) Clostridium difficile infection: new approaches to prevention, non-antimicrobial treatment, and stewardship. Expert Rev Anti Infect Ther 15:1027-1040. [Crossref]

48. Evans CT, Johnson S (2015) Prevention of Clostridium difficile Infection With Probiotics. Clin Infect Dis 60 Suppl 2: S122-128. [Crossref]
49. Carvour ML, Wilder SL, Ryan KL, Walraven C, Qeadan F, et al. (2019) Predictors of Clostridium difficile infection and predictive impact of probiotic use in a diverse hospital-wide cohort. Am J Infect Control 47: 2-8. [Crossref]

50. Dudzicz S, Kujawa-Szewieczek A, Kwiecien K, Wiecek A, Adamczak M (2018) Lactobacillus plantarum 299v Reduces the Incidence of Clostridium difficile Infection in Nephrology and Transplantation Ward-Results of One Year Extended Study. Nutrients 10: e1574. [Crossref]

Copyright: $@ 02019$ Lis L. This is an open-access article distributed under the terms of the Creative Commons Attribution License, which permits unrestricted use, distribution, and reproduction in any medium, provided the original author and source are credited. 